\title{
Open Educational Resources (OER) dan Penerapannya pada Perpustakaan Institut Agama Islam Negeri Curup
}

\author{
Rahmat Iswanto \\ Institut Tinggi Agama Islam Negeri (IAIN) Curup \\ e-mail: rahmatiswanto@iaincurup.ac.id
}

\begin{abstract}
This paper examines the concept of open educational resources developing in the world of education and libraries and the application of OER development research results to the IAIN Curup library. The problems were how the limitations of the OER and the models developed were, how was the development carried out by the IAIN Curup library, and how the application of the OER model developed in the IAIN Curup library was applied. The method used in this scientific paper is to explain the OER concept based on several sources, both articles and books. Another method is to describe the results of interviews with research subjects related to the application of OER at the IAIN Curup library. The results are a conceptual framework generated from some articles and books as well as an assessment of the application of OER in the IAIN Curup library. The form of OER service is a form of business development to provide the role of information providers in the world of education which must always be maintained and developed by educational institutions by utilizing technology. Meanwhile, the application of OER in the IAIN Curup library is still not optimal due to several constraints both internally and externally.
\end{abstract}

Keywords: Academic Library; Open Educational Resources; Open Access

\begin{abstract}
Abstrak
Tulisan ini mengkaji konsep open educational resources yang berkembang di dunia pendidikan dan perpustakaan serta meneliti penerapan hasil penelitian pengembangan OER pada perpustakaan IAIN Curup. Permasalahan yang diangkat adalah bagaimana batasan OER dan model-model yang dikembangkan, bagaimana pengembangan yang dilakukan oleh perpustakaan IAIN Curup, dan bagaimana penerapan model OER yang dikembangkan pada perpustakaan IAIN Curup. Metode yang digunakan dalam tulisan ilmiah ini adalah memaparkan konsep OER berdasarkan beberapa sumber, baik artikel maupun buku. Metode lain adalah mengambarkan hasil wawancara subyek penelitian terkait penerapan OER pada perpustakaan IAIN Curup. Hasil yang diperoleh dari tulisan ini adalah kerangka konseptual yang
\end{abstract}

Tik Ilmeu : Jurnal Ilmu Perpustakaan dan Informasi IAIN Curup | p-issn: 2580-3654; e-issn:2580-3662

DOI: $10.29240 /$ tik.v5i1.2772 
dihasilkan dari sumber data berupa artikel dan buku serta penilaian terhadap penerapan OER pada perpustakaan IAIN Curup. Bentuk pelayanan OER merupakan suatu pengembangan usaha memberikan peran penyedia informasi dalam dunia pendidikan yang harus selalu dipelihara dan dikembangkan oleh lembaga pendidikan dengan memanfaatkan teknologi. Sementara penerapan OER pada perpustakaan IAIN Curup masih belum maksimal disebabkan beberapa kendala baik secara internal maupun secara eksternal.

Kata Kunci: Perpustakaan Akademik; Sumber Pendidikan Terbuka; Akses Terbuka

\section{A. PENDAhuluan}

Perpustakaan dengan salah satu fungsinya menyediakan sumber informasi selalu berusaha memberikan perannya bagi masyarakat pemustakannya. Sumber informasi yang dikembangkan dalam berbagai bentuk untuk memenuhi kebutuhan pemustaka tidak dapat disediakan dengan mudah. Penyediaan sumber informasi terkendala dari beberapa faktor yaitu sistem manajemen pembinaan koleksi yang kurang baik, terbatasnya anggaran yang disediakan dan kemajuan bidang keilmuan yang sangat pesat.

Dalam kemajuan teknologi saat ini, informasi yang dapat diakses oleh pemustaka membantu perpustakaan melaksanakan perannya lebih baik. Sehingga banyak perpustakaan khususnya perpustakaan perguruan tinggi menerapkan open access sebagai bentuk keterbukaan informasi meskipun dalam penerapannya masih sesuai dengan pandangan pemegang wewenang penyelenggaraan pendidikan. Pada tulisan Eko Handoyo dan Atin Istiarni mengenai faktor-faktor yang mempengaruhi pelaksanaan kebijakan open access di perpustakaan perguruan tinggi negeri di Jawa Tengah bahwa faktor yang memperngaruhi pelaksanaan open acces adalah 1). Hak cipta masih ada pada penulis 2). Belum ada kebijakan tertulis 3). Kepala perpustakaan tidak memiliki hak penuh untuk menentukan kebijakan 4). terdapat perbedaan pandangan antar pemangku jabatan terhadap repositori institusi akses terbuka berdampak pada kebijakan akses dan aksesibilitas ke repositori institusi, bahwa dalam rangka perlindungan karya akademik diterapkan pembatasan akses. (Handoyo \& Istiarni, 2020)

Istilah keterbukaan informasi yang semakin marak di dunia pendidikan maka perlu kita perlu melihat kebijakan pemerintah dan aturan internasional. Payung hukum terhadap keterbukaan informasi publik tidak hanya menjamin hak warga negara. Di sisi lain, badan publik juga harus 
menyadari bahwa ada informasi yang dapat dibagikan atau dibuka untuk masyarakat dijamin oleh Undang-undang. (Safitri, 2019). Sementara dalam tulisan lain keterkaitan antara Undang-Undang Kearsipan (UUK) 43 tahun 2009 dan Undang-Undang Keterbukaan Informasi Publik (UUKIP) No 14 tahun 2008 mengenai filosofi lahirnya undang-undang tersebut, analisis kontennya, dan implementasi di kehidupan masyarakat. (Aryasatya \& Katili, 2018)

Pada sumber lain meletakkan batasan open access sebagai Open access (OA) literature is digital, online, free of charge, and free of most copyright and licensing restrictions. (Suber, 2012) Ditulisan lain untuk menggambarkan keterbukaan informasi adalah mengenai keterbukaan sain. Sebagaimana perkembangan konsep dan implementasi open science yang dapat diadopsi untuk meningkatkan dampak saintifik sebagaimana yang dipaparkan Dasapta Erwin Irawan dkk dalam tulisan berjudul Penerapan Open Science di Indonesia Agar Riset Lebih Terbuka, Mudah Diakses, dan Meningkatkan Dampak Saintifik. Keterbukaan sain lebih kepada keterbukaan hasil penelitian yang dilakukan peneliti lain yang dapat menghasilkan sesuatu yang baru yang lebih baik. (Irawan, 2017)

Dalam suatu kebutuhan penelitian, ada kalanya peneliti membutuhkan arsip. Dalam hal ini juga sudah dikeluarkan peraturan penggunaan arsip secara terbuka demi kebutuhan tersebut. Tujuan peraturan tersebut adalah untuk memberikan panduan kepada lembaga kearsipan dalam menyediakan akses arsip yang dinyatakan tertutup dan layanan yang terkait dengan pemanfaatan arsip statis sebelum 25 (dua puluh lima) tahun masa penyimpanan untuk kepentingan penelitian, pengembangan ilmu pengetahuanserta penyelidikan, dan penyidikan. (PERATURAN KEPALA ARSIP NASIONAL REPUBLIK INDONESIA NOMOR 26 TAHUN 2016 TENTANG PEDOMAN KETERBUKAAN ARSIP STATIS UNTUK PENELITIAN DAN PENGEMBANGAN ILMU PENGETAHUAN SERTA PENYELIDIKAN DAN PENYIDIKAN, 2016)

Bagi perpustakaan IAIN Curup dalam hal ini, sangat merasakan keterbatasan sebagaimana di atas. Untuk itu pengelola perpustakaan merasa perlu mencari langkah-langkah dalam memenuhi kebutuhan pemustaka. Open educational resources (OER) merupakan isu yang menarik bagi lembaga penyedia informasi di lingkungan pendidikan, tak terkecuali bagi pengelola perpustakaan IAIN Curup. Oleh karena itu pada tahun 2020 pustakawan melakukan penelitian dengan mengembangkan suatu manajemen OER sehingga akan menghasilkan suatu layanan baru yang diharapkan. 
Pada penerapannya masih dijumpai kendala sehingga anggapan bahwa bentuk sumber terbuka bagi lembaga pendidikan ini sangat efektif masih perlu dikaji ulang. Pengkajian OER dalam hal ini adalah untuk mencari tau apa sesungguhnya bentuk layanan OER yang dikembangkan oleh pengembang awal, bagaimana prinsip pelaksanaan layanan ini, sejauhmana layanan OER ini dapat diterapkan khusunya bagi masyarakat pemustaka perpustakaan IAIN Curup.

Beranjak dari asumsi bahwa ada konsep dasar yang harus dijadikan pedoman bagi pustakawan dan ada kekurangan yang dimiliki perpustakaan IAIN Curup mengenai penerapan OER yang masih dirasakan belum maksimal, maka tulisan ini dilakukan. Harapan tulisan ini akan menjadikan suatu usaha yang bernilai evaluasi dan manfaat bagi pengelola perpustakaan.

\section{B. HASIL DAN PEMBAHASAN}

\section{Batasan Open Educational Resources}

Open Educational Resources (OERs) adalah materi pengajaran, pembelajaran, dan penelitian yang tersedia secara gratis, dan tanpa atau hanya batasan terbatas, untuk mendukung akses ke pengetahuan. OER menjadi semakin penting di sektor pendidikan. Mereka telah membuktikan manfaatnya dengan menyediakan akses yang demokratis dan setara ke pengetahuan, mendukung pembelajaran seumur hidup dan informal, dan menawarkan sumber pengetahuan yang beragam. Pustakawan membantu mewujudkan OER: mereka membuatnya tersedia dan dapat diakses, serta mendorong produksi, penggunaan, dan penyebarannya.

Definisi UNESCO mengenai OERs adalah "Open Educational Resources (OER) are teaching, learning and research materials in any medium - digital or otherwise - that reside in the public domain or have been released under an open license that permits no-cost access, use, adaptation and redistribution by others with no or limited restrictions". Dengan demikian definisinya Open Educational Resources (OER) adalah materi pengajaran, pembelajaran, dan penelitian dalam media apa pun digital atau lainnya - yang berada di domain publik atau telah dirilis di bawah lisensi terbuka yang mengizinkan akses, penggunaan, adaptasi, dan distribusi ulang tanpa biaya oleh orang lain dengan tidak ada atau batasan terbatas. (Rubow, 2015)

Ada beberapa definisi Sumber Daya Pendidikan Terbuka (Open Educational Resources (OERs), tetapi karakteristik utamanya adalah sebagai berikut: - Jenis sumber daya: OER bisa lebih atau kurang dari semua jenis materi. Menurut William and Flora Hewlett Foundation, "sumber daya 
pendidikan terbuka mencakup kursus lengkap, materi kursus, modul, buku teks, video streaming, tes, perangkat lunak, dan alat, materi, atau teknik lain yang digunakan untuk mendukung akses ke pengetahuan". Menurut OECD, perpustakaan online Organisasi untuk Kerjasama Ekonomi dan Pembangunan "OER mencakup konten pembelajaran, perangkat lunak untuk mengembangkan, menggunakan, dan mendistribusikan konten, dan sumber daya implementasi seperti lisensi terbuka". - Tujuan: Tujuan sumber daya adalah belajar mengajar, dan dapat mencakup penelitian. - Format atau media penggunaan: media apa pun, digital atau lainnya. - Status hak cipta: materi harus berada di domain publik atau telah dirilis di bawah lisensi terbuka yang mengizinkan akses, penggunaan, adaptasi, dan distribusi ulang tanpa biaya oleh orang lain tanpa atau batasan terbatas; atau ditawarkan secara bebas dan terbuka untuk digunakan dan digunakan kembali.

Ada beberapa alasan mengapa OER dianggap sebagai alternatif yang baik, atau setidaknya pelengkap yang baik, dari buku teks tradisional untuk mendukung pembelajaran: 1. OER dapat memberikan akses pengetahuan yang demokratis dan adil, artinya setiap orang dapat mengakses dan menggunakan sumber daya tanpa memandang pendapatan tingkat, selama tidak ada hambatan teknis. Mengingat biaya buku teks yang terkadang tinggi dan tidak terjangkau, OER menawarkan solusi bagi mereka yang menghadapi keterbatasan ekonomi. Beberapa orang berpendapat bahwa pendidikan publik yang sebenarnya tidak boleh meninggalkan masalah keterjangkauan buku teks yang tidak terselesaikan, yang membuat beberapa siswa tidak memiliki akses ke bagian penting dari proses pembelajaran mereka. 2. OER dapat mendukung pembelajaran seumur hidup dan non-formal, dengan tersedia bagi orang-orang di luar sistem pendidikan formal, tanpa memandang usia dan studi sebelumnya. 3. OER dapat menawarkan pengetahuan yang lebih beragam daripada buku teks tradisional. Melalui OER, materi berasal dari berbagai sumber, wilayah berbeda, mencerminkan berbagai perspektif, dan tersedia dalam berbagai bahasa. 4. OER juga dapat menciptakan pengalaman yang lebih dinamis bagi pelajar, yang alih-alih mendengarkan atau membaca secara pasif, dapat mengambil bagian dalam penciptaan sumber daya pendidikan. 5. Kemungkinan orang lain untuk mereview suatu karya dan melakukan koreksi atau perbaikan juga merupakan sarana untuk meningkatkan kualitas dan relevansi materinya. Selain itu, ketika membagikan sesuatu secara online, pembuatnya juga cenderung berusaha lebih keras untuk memastikan kualitasnya mengingat eksposur mereka akan lebih luas. 6. OER umumnya memungkinkan untuk digunakan kembali, memungkinkan orang lain untuk menyesuaikan ide-ide yang baik untuk konteks mereka sendiri. Pendidik lain dapat menemukan, mengubah materi 


\section{4 | Rahmat Iswanto : Open Educational Resources $($ OER)...}

menggunakan contoh dan referensi lokal, dan menggunakan serta membagikannya sendiri.

OER bukanlah gerakan terpusat, meskipun ada beberapa koordinasi, dan ada banyak inisiatif berbeda. Istilah OER pertama kali diadopsi pada Forum UNESCO 2002 tentang Dampak Open Courseware untuk Pendidikan Tinggi di Negara Berkembang. Organisasi internasional, serta pemerintah regional dan nasional, telah mengeksplorasi (dan dalam kesempatan tertentu mendorong) pembuatan dan penggunaan OER. Beberapa organisasi, di antaranya perpustakaan dan badan penelitian, serta yang lain seperti Creative Commons, terlibat dalam upaya advokasi untuk mempengaruhi kebijakan di seluruh dunia.

Di tingkat internasional, UNESCO telah merilis banyak dokumen dan pedoman, dan saat ini sedang mempertimbangkan pembuatan draf rekomendasi.

Di tingkat nasional, inisiatif juga diterapkan, seperti yang direkomendasikan oleh SPARC dalam Buku Panduan Kebijakan Negara Bagian OER dengan fokus pada masing-masing negara bagian AS. Contohcontoh yang disoroti oleh dokumen tersebut termasuk pembentukan program hibah OER, atau persyaratan untuk menandai penggunaan OER dalam jadwal kursus, antara lain. Nigeria menawarkan contoh inisiatif lain di tingkat nasional yang berupaya memperkuat komitmen untuk OER oleh Institusi Pendidikan Tinggi dan semua pemangku kepentingan terkait di negara tersebut, seperti yang disajikan dalam laporan Kebijakan Sumber Daya Pendidikan Terbuka untuk Pendidikan Tinggi di Nigeria.

Open Educational Resources (OER) menghapus batasan untuk pelajar dan pendidik berdasarkan sifatnya. OER tidak dikenai biaya langsung kepada pengguna akhir dan, dalam banyak kasus, dapat diakses secara online secara terbuka. Pertumbuhan minat baru-baru ini pada OER memiliki beberapa pendorong, ideologis, politik dan ekonomi, tidak satupun yang dengan sendirinya menjelaskan bagaimana pembelajaran akan didukung atau membantu kita untuk mengembangkan model dan pembelajaran yang efektif. (McGrealv, 2013)

\section{Model-model Open Educational Resources}

Daftar lembaga, organisasi, dan individu yang terlibat dalam pengembangan dan promosi OER terus bertambah, dan pertumbuhannya semakin cepat dalam beberapa tahun terakhir. Namun, di bawah ini ada tiga lembaga aktif secara global yang patut disoroti. 
The William and Flora Hewlett Foundation Yayasan yang didirikan oleh salah satu pendiri Hewlett-Packard Company, dan istrinya, memiliki banyak bidang minat filantropis, mulai dari perkembangan global dan populasi hingga lingkungan. Namun, secara signifikan yayasan telah banyak berinvestasi dalam pendidikan, terutama dalam mendukung gerakan pendidikan terbuka. Menariknya, Forum UNESCO 2002 tentang Dampak Open Courseware untuk Pendidikan Tinggi di Negara Berkembang dan Kongres OER Dunia 2012, yang diselenggarakan oleh Commonwealth of Learning (COL) dan UNESCO, didanai oleh Hewlett Foundation. Seperti yang ditunjukkan oleh situs webnya, The William and Flora Hewlett Foundation mendukung: • Mengembangkan kurikulum OER untuk K-12 dan community college; - Membantu perluasan jaringan OER, dan mengembangkan pedoman dan alat untuk lapangan; - Mempromosikan kebijakan atau strategi yang menciptakan dana dan insentif, atau menyediakan komunikasi dan bantuan teknis kepada pembuat kebijakan, untuk memajukan akses yang lebih besar ke pembelajaran melalui OER; • Meneliti dan mengevaluasi dampak OER pada pengajaran dan pembelajaran; - Mengembangkan model OER yang inovatif.

UNESCO Organisasi Pendidikan, Ilmu Pengetahuan, dan Kebudayaan Perserikatan Bangsa-Bangsa (UNESCO) percaya bahwa OER "memberikan peluang strategis untuk meningkatkan kualitas pendidikan serta memfasilitasi dialog kebijakan, berbagi pengetahuan, dan pembangunan kapasitas". Deklarasi Paris OER, yang diadopsi selama Kongres OER Dunia yang diadakan pada bulan Juni 2012 di kantor pusat UNESCO, merupakan langkah penting untuk pengembangan kebijakan nasional yang mendukung OER. Sepuluh poin deklarasi tersebut mendorong pemerintah untuk berkontribusi pada kesadaran dan penggunaan OER serta untuk mengembangkan strategi dan kebijakan untuk mengintegrasikan OER dalam pendidikan. Pada 2013, UNESCO mengadopsi kebijakan akses terbuka untuk semua terbitannya, sejalan dengan komitmennya untuk mempromosikan dan mendukung OER dan OA.

Commonwealth of Learning COL adalah sebuah organisasi antar pemerintah yang dibuat oleh Commonwealth Heads of Government untuk mendorong pengembangan dan berbagi pengetahuan, sumber daya, dan teknologi pembelajaran terbuka / pendidikan jarak jauh. COL selama bertahun-tahun telah berada di garis depan gerakan OER, memfasilitasi berbagai inisiatif. Itu adalah organisasi antar pemerintah pertama yang mengadopsi lisensi terbuka untuk semua terbitannya. COL mendorong pemerintah untuk secara resmi mengakui pentingnya berbagi OER, melalui pengembangan kebijakan — baik sebagai kebijakan yang berdiri sendiri atau 
dalam ranah yang lebih luas dari kebijakan TIK dalam pendidikan. COL telah mengembangkan beberapa sumber daya di OER untuk membangun kapasitas guru dan mengembangkan materi belajar mengajar sebagai OER. Banyak sumber daya semacam itu tersedia di situs webnya, dan juga di kantor regionalnya di New Delhi: Pusat Media Pendidikan Persemakmuran untuk Asia (CEMCA).

\section{Pengembangan Open Educational Resources pada Perpustakaan IAIN Curup}

Rahmat Iswanto dan Jurianto dalam tulisannya yang berjudul Pengembangan model manajemen Open Educational Resources (OER) Perpustakaan Institut Agama Islam Negeri Curup melakukan proses pengembangan dengan menghasilkan produk OER yang disesuaikan dengan kebutuhan pemustaka perpustakaan IAIN Curup. Model manajemen OER yang dikembangkan meliputi empat tahapan; pertama perencanaan yang terdiri dari analisis kebutuhan, identifikasi, dan verifikasi atau persiapan. kedua pengorganisasian yaitu kegiatan pengolahan. Ketiga pelayanan dan promosi. keempat ialah evaluasi. Bentuk pengembangan ini diharapkan menjadi suatu model layanan sumber belajar yang melengkapi pemenuhan kebutuhan pemustaka. (Iswanto \& Jurianto, 2020)

Pengembangan produk OER di Perpustakaan IAIN Curup dilakukan dengan mengadopsi aplikasi open sources yang disediakan pada media informasi online lihat (Iswanto \& Jurianto, 2020). Kemudian dengan mempertimbangkan kondisi perpustakaan terutama kesiapan SDM maka bentuk produk yang dikembangkan disesuaikan.

\section{Penerapan Open Educational Resources pada Perpustakaan IAIN Curup}

Open Educational Resources pada Perpustakaan IAIN Curup disediakan dalam sebuah server institusi dengan alamat http://oer.iaincurup.ac.id. Model pengelolaan OER di Perpustakaan IAIN Curup memiliki tahapan yang harus dilakukan di antaranya, tahap perencanaan atau persiapan, tahap pengorganisasian, tahap pengelolaan, pelayanan (actualizing), dan tahap evaluasi. (Iswanto \& Jurianto, 2020).

Model OER di Perpustakaan IAIN Curup adalah bentuk yang dimulai dari perencanaan, pengorganisasian, pengolahan, kemudian baru ada pelayanan. Dengan demikian yang terlibat dalam kegiatan ini adalah pimpinan perpustakaan, pustakawan, dan pemustaka. Maka bagaimana penilaian terhadap eksistensi dan penerapan layanan OER di Perpustakaan 
IAIN Curup dapat diungkapkan dan digambarkan melalui informasi dari ketiga subyek tersebut.

Pimpinan perpustakaan memaparkan bahwa kehadiran layanan OER di Perpustakaan IAIN Curup meningkatkan peran perpustakaan dan nilai perpustakaan di mata pemustaka dan penilai lembaga perpustakaan. Akan tetapi kesulitannya adalah keterbatasan kapasitas server institusi sehingga sangat sering layanan ini tertutup dari akses. Permasalahan lain adalah sosialisasi yang tidak maksimal dengan layanan baru ini baik kepada pimpinan institusi maupun kepada pemustaka. Ketersediaan materi terbuka atau materi gratis yang dijumpai oleh pihak perpustakaan masih perlu dicari dengan intensif.

Pustakawan belum memahami dengan baik OER di Perpustakaan IAIN Curup sehingga pelaksanaan layanan ini boleh disebut tidak berjalan dengan baik. Pustakawan mengharapkan adanya kegiatan pelatihan. Hal ini disampaikan oleh beberapa pustakawan Perpustakaan IAIN Curup.

Pemustaka belum merasakan layanan OER di Perpustakaan IAIN Curup dikarenakan akses untuk menuju OER di Perpustakaan IAIN Curup belum berhasil dilakukan. Meskipun demikian pemustaka yang berhasil melihat layanan ini menilai bentuk OER di Perpustakaan IAIN Curup sangat menarik dan mengharapkan konten yang termuat semakin dikembangkan.

\section{DAFTAR RUJUKAN}

\section{PERATURAN KEPALA ARSIP NASIONAL REPUBLIK INDONESIA $\begin{array}{lllll}\text { NOMOR } & 26 & \text { TAHUN } & 2016 & \text { TENTANG } \\ \text { PEDOMAN }\end{array}$ KETERBUKAAN ARSIP STATIS UNTUK PENELITIAN DAN PENGEMBANGAN ILMU PENGETAHUAN SERTA PENYELIDIKAN DAN PENYIDIKAN, 26 (2016).}

Aryasatya, A. B., \& Katili, A. Y. (2018). Undang-Undang Kearsipan dan Keterbukaan Informasi Publik dalam Menjawab Kebutuhan Informasi Masyarakat. Libraria, 439-460.

Handoyo, E., \& Istiarni, A. (2020). Faktor-faktor yang mempengaruhi pelaksanaan kebijakan open access di perpustakaan perguruan tinggi negeri di Jawa Tengah. VISI PUSTAKA, 17-28.

Irawan, D. E. (2017). Penerapan Open Science di Indonesia Agar Riset Lebih Terbuka, Mudah Diakses, dan Meningkatkan Dampak Saintifik. Berkala Ilmu Pepustakaan dan Informasi, 25-36. 
88 | Rahmat Iswanto : Open Educational Resources $($ OER)...

Iswanto, R., \& Jurianto. (2020). Pengembangan Model Manajemen Open Educational Resources (OER) Perpustakaan Institut Agama Islam Negeri Curup. Jurnal Kajian Informasi \& Perpustakaan, 171-188.

McGrealv, R. d. (2013). Open Educational Resources: Innovation, Research and Practice. Vancouver: Commonwealth of Learning and Athabasca University.

Rubow, L. d. (2015). Understanding Open Educational Resources. California: Commonwealth of Learning.

Safitri, D. (2019). Peranan pengelola rekod dan arsip organisasi pada layanan informasi publik : kewajiban organisasi publik menghadirkan PPI. Jurnal Vokasi Indonesia, 48-57.

Suber, P. (2012). Open Access. Cambridge: Press Essential Knowledge. 